\title{
TITLE: PLASMA RANTES CONCENTRATIONS DURING ON-PUMP OR OFF-PUMP CORONARY ARTERY BYPASS GRAFTING SURGERY
}

Tso-Chou Lin MD, Chi-Yuan Li MS MD, Chih-Shung Wong PhD MD, Shung-Tai Ho MS MD. Department of Anesthesiology, Tri-service General Hospital, National Defense Medical Center, National Defense University, \#325, Section 2, Cheng-Gong Road, 114 Nei-Hu Dist, Taipei, Taiwan, ROC.

INTRODUCTION: Cardiopulmonary bypass (CPB) is known to induce platelet activation and a systemic inflammatory response. RANTES (regulated on activation, normal $\mathrm{T}$ cells expressed and secreted), a CC-chemokine with a potent chemoattractant activity, is secreted by lymphocytes and constitutively present in platelet $\alpha$-granules and released upon platelet activation. Decreased levels of RANTES (1) and lymphocyte depletion (2) have been observed in patients following CPB. The data on RANTES after off-pump cardiac surgery are scarce. The present study was designed to determine the RANTES levels and platelet depletion in patients undergoing on-pump or off-pump cardiac surgery.

METHODS: After obtaining the approval of the ethics committee and written informed consents, fourteen patients undergoing elective coronary artery bypass grafting (CABG) surgery with or without $\mathrm{CPB}$ were included in this study. Blood was collected at seven sequential time points and analyzed for RANTES concentrations. The postoperative platelet and lymphocyte counts were examined.

RESULTS: The plasma levels of RANTES in patients with CPB decreased significantly 2 to 6 hours after the start of CPB $(3,200 \pm 700 \mathrm{pg} / \mathrm{mL}$ and 2,900 $\pm 800 \mathrm{pg} / \mathrm{mL}$, both $P<0.05$, compared with 7,200 $\pm 1,500 \mathrm{pg} / \mathrm{mL}$ before induction), while the RANTES levels in patients with off-pump CABG did not $(2,500 \pm 900 \mathrm{pg} / \mathrm{mL}, P=0.165$ at 4 hours after application of a stabilization device, compared with $6,100 \pm 2,700 \mathrm{pg} / \mathrm{mL}$ before induction). In addition, both of the postoperative platelet counts $(148,000 \pm 11,000 / \mu \mathrm{L}, P<0.05$, compared with $213,000 \pm$ $26,000 / \mu \mathrm{L}$ before operation) and total lymphocytes $(862 \pm 159 / \mu \mathrm{L}, P<0.01$, compared with $1,711 \pm 196 / \mu \mathrm{L}$ before operation) decreased significantly at 4-6 hours after beginning CPB. DISCUSSION: The present study demonstrated that CPB causes a decrease in the concentration of plasma RANTES. The corresponding platelet and lymphocyte depletion suggests that RANTES is derived primarily from platelets and lymphocytes following CPB-induced inflammatory and immune response.

\section{REFERENCES:}

1. Ann Thorac Surg 2001; 71:233-237.

2. Ann Thorac Surg 1987; 44: 277-282. 